\title{
UPAYA PENINGKATAN KEMAMPUAN MOTORIK HALUS (KOLASE) ANAK TK KELOMPOK B MELALUI PENERAPAN METODE DEMONSTRASI DAN PEMBERIAN TUGAS DENGAN MEDIA KULIT TELUR
}

\author{
Hadiyati \\ TK Nurussalam Kota Jambi \\ Email: tknurussalam@gmail.com
}

\begin{abstract}
Abstrak
Salah satu bentuk satuan pendidikan prasekolah di jalur pendidikan sekolah adalah Taman Kanak-kanak. Penelitian ini bertujuan untuk mendeskripsikan penggunaan metode demonstrasi dan pemberian tugas dengan berbagai media dalam mengembangkan ketrampilan motorik halus (kolase) anak di TK NURUSSALAM.

Dari hasil penelitian tindakan kelas pada Rencana Kegiatan Harian menunjukkan bahwa kemampuan kolase anak kelompok B di TK NURUSSALAM sudah cukup baik. Hal ini dapat dilihat pada tabel 4.1, di mana pelaksanaan tindakan guru dengan menggunakan media kulit telur dan membagikannya kepada masing-masing anak, kemudian masing-masing anak diminta untuk mempraktekkan langsung yang didemonstrasi Guru.
\end{abstract}

\section{Kata Kunci: Kolase, Metode Pemberian Demonstrasi dan Tugas}

\section{A. PENDAHULUAN}

\section{Latar Belakang}

Pendidikan Taman Kanak - kanak merupakan pendidikan anak usia dini pada jalur formal yang melayani anak usia 4 - 6 tahun. Tujuan Pendidikan Taman Kanak-kanak adalah membantu berbagai potensi, yang meliputi sikap, perilaku, bahasa, kognitif, fisik motorik dan seni untuk siap memasuki jenjang pendidikan berikutnya.

Untuk mencapai atau mewujudkan hal-hal tersebut sangatlah guru yang profesional, sarana dan prasarana yang memadai, salah satunyaadalah media yang menarik dalam kegiatan pembelajaran.

Seperti yang terjadi pada Taman Kanak-kanak NURUSSALAM Kelompok B Tahun Ajaran 2017/2018 semester pertama pengembangan seni khususnya pada indikator kolase dengan berbagai media sebagian anak kesulitan,

VOLUME 1, NO. 2 Juli - Desember ' 
sehingga anak kurang mencapai apa yang diharapkan guru. Berdasarkan pengamatan yang terjadi di kelas, hasil belajar anak pada indikator tersebut kurang memuaskan. Banyak anak yang merasa bosan saat diberikan kegiatan tersebut,dan juga banyak anak yang tidak mau menyelesaikan kegiatan atau tugas yang diberikan guru.

Dengan metode penelitian tindakan kelas diharapkan peningkatan hasil belajar anak dalam kegiatan kolase dengan berbagai media dapat tercapai dengan optimal.

\section{Rumusan Masalah}

Berdasarkan analisis di atas, Rumusan Masalah yang ada adalah "Apakah dengan metode demonstrasi dan pemberian tugas serta penggunaan media kulit telur dapat meningkatkan kemampuan membuat kolase anak di Taman Kanak kanak NURUSSALAM Kelompok B?”

\section{Tujuan Penelitian}

Penelitian ini bertujuan untuk mendeskripsikan penggunaan metode demonstrasi dan pemberian tugas dengan berbagai media dalam mengembangkan ketrampilan motorik halus (kolase) anak di TK NURUSSALAM.

\section{Manfaat Penelitian}

a. Manfaat bagi Anak

Meningkatkan hasil belajar anak pada kegiatan kolase dengan berbagai media.

b. Manfaat bagi Guru

- Meningkatkan kemampuan Guru sebagai fasilitator dan motivator.

- Memberi gambaran pada Guru tentang cara pembelajaran membuat kolase

c. Manfaat bagi Sekolah

Meningkatkan kualitas / mutu TK yang bersangkutan. 


\section{B. KAJIAN PUSTAKA}

\section{Pengertian Motorik Halus}

Motorik halus adalah gerakan yang menggunakan otot - otot halus atau sebagian anggota tubuh tertentu, yang dipengaruhi oleh kesempatan untuk belajar dan berlatih, tidak terlalu membutuhkan tenaga, akan tetapi membutuhkan koordinasi yang cermat serta ketelitian. Misalnya, kemampuan memindahkan benda dari tangan, mencoret-coret, menyusun balok, menggunting, menulis, dan sebagainya. Perkembangan motorik ini sangat penting agar anak bisa berkembang dengan optimal.

Perkembangan motorik halus anak Taman Kanak-kanak ditekankan pada koordinasi gerakan motorik halus, dalam hal ini berkaitan dengan kegiatan meletakkan atau memegang suatu objek dengan menggunakan jari tangan. Pada usia 4 tahun koordinasi gerakan motorik halus anak sangat berkembang, bahkan hampir sempurna. Pada usia 5 atau 6 tahun koordinasi gerakan motorik halus berkembang pesat. Pada masa ini anak telah mampu mengkoordinasikan gerakan visual motorik, seperti mengkordinasikan gerakan mata dengan tangan, lengan, dan tubuh secara bersamaan, antara lain dapat dilihat pada waktu anak menulis/menggambar.

\section{Metode Demonstrasi dan Pemberian Tugas}

Menurut Muhibbin Syah, 2000 (dalam Metode Pengembangan Perilaku dan Kemampuan Dasar Anak Usia Dini). Metode Demonstrasi adalah metode mengajar dengan cara memperagakan barang kejadian, aturan dan urutan melakukan suatu kegiatan, baik secara langsung maupun melalui penggunaan media pengajaran yang relevan dengan pokok bahasan atau materi yang sedang disajikan.

Menurut Moeslichatoen, 2004 (dalam Metode Pengembangan Perilaku dan Kemampuan Dasar Anak Usia Dini) hal-hal yang perlu diperhatikan dalam memberikan tugas kepada anak adalah :

1. Pemberian tugas adalah proses integral dalam kegiatan pengembangan, maka tujuan tugas merupakan bagian penting sehingga tugas yang diberikan dapat 
dilakanakan dengan sebaik-baiknya.

2. Pemberian tugas tidak sekedar menyibukkan anak melainkan dapat memberikan sumbangan terhadap tujuan belajar yang diharapkan.

3. Pemberian tugas harus memberikan pengenalankepada anak untuk bekerja dengan lebih baik.

4. Pemberian tugas harus menantang pengembangankreativitas.

5. Pemberian tugas harus menumbuhkan kesadarandiri sendiri bukan untuk pendidik.

\section{Media}

Menurut Pamadhi, Hajar dan Sukardi S. Evan (2008) Media adalah bahan yang dapat digunakan ntuk menuangkan gagasanseseorang seperti kertas, kanvas, kain, papan tripleks, haid barel, keramik, kaleng, plastik, spon, daun, pita, serta bahan yang lainnya.

Dari pendapat di atas dapat disimpulkan bahwa media adalah komponen sumber belajar siswa yang dapat mendorong siswa untuk belajar, sehingga dapat mendorong anak untuk berimajinasi dan mengembangkan potensi yang dimiliki melalui kegiatan bermain.

\section{Kolase}

Kolase berasal dari bahasa Perancis, yaitu "Coller" yang berarti lem/tempel, jadi bisa dikatakan Kolase adalah sebuah teknik menempel unsur-unsur yang berbeda (bisa berupa kain, kertas, kayu, dan lain-lain) ke dalam sebuah frame sehingga menghasilkan sebuah karya seni yang baru.

Secara umum kolase adalah teknik menggabung beberapa objek menjadi satu. Tidak hanya asal jadi, tapi objek - objek itu harus mampu bercerita untuk menciptakan kesan tertentu. Kolase merupakan perkembangan lebih lanjut dari seni lukis. Di mana pada awal abad ke-20 para perupa sering menambahkan (menempelkan) unsur-unsur yang berbeda ke dalam lukisan mereka seperti potongan-potongan kain, kayu ataupun kertas koran, namun 
memang ada perbedaan yang sangat signifikan antara seni kolase dan seni lukis. Di dalam karya seni kolase selain aspek formal seni yang dikedepankan meliputi nilai-nilai dasar keindahan, tata penyusunan objek ke dalam frame (layout), kontur, bentuk objek dan warna sebagaimana yang biasa disodorkan oleh karya seni lukis dan desain grafis tetapi juga aspek ilustratif yaitu meliputi aspek konten material dan bentuk gambar kolase itu sendiri.

Hal ini akan menimbulkan kesan yang berbeda dari penikmat seni/audience ketika mengapresiasi karya kolase, karena disodori keunikan yang ditimbulkan oleh penyusunan material-material yang berbeda di dalam sebuah frame karya seni, hal yang tidak dapat dijumpai dari seni lukis.

\section{METODE PENELITIAN}

\section{Jenis penelitian}

Jenis penelitian yang digunakan yaitu Penelitian Tindakan Kelas.

\section{Prosedur Penelitian}

Pelaksanaan PTK yang dilakukan penulis adalah :

a. Melaksanakan refleksi, berdiskusi dengan teman sejawat, dan meminta saran/bimbingan dari supervisor untuk mengidentifikasi masalah, menganalisis masalah dan merumuskan masalah

b. Menyusun penelitian

c. Melaksanakan tindakan penelitian

d. Menganalisis data yang diperoleh pada waktu melaksanakan tindakan penelitian kemudian menarik kesimpulan. Penelitian ini bertujuan untuk perbaikan pembelajaran di TK NURUSSALAM Kelompok B. Tujuan utamanya adalah meningkatkan kemampuan motorik halus kolase dengan menggunakan berbagai media melalui metode demonstrasi dan pemberian tugas pada anak kelompok B TK NURUSSALAM Tahun Pelajaran 2018/2019 yang sesuai dengan tingkat perkembangan motorik halus anak. 


\section{Rencana Kegiatan}

- Perencanaan

- Pelaksanaan Tindakan:

- Observasi

- Refleksi

\section{HASIL PENELITIAN DAN PEMBAHASAN}

\section{Hasil Penelitian}

Dari perencanaan, pelaksanaan tindakan, observasi, dan refleksi yang telah dilakukan oleh guru pada Rencana Kegiatan Harian tentang kemampuan membuat kolase dengan media kulit telur didapatkan hasil sebagai berikut:

Hasil Nilai Anak Kelompok B TK NURUSSALAM pada pembuatan kolase;

\begin{tabular}{|c|l|c|c|c|c|}
\hline No & \multicolumn{1}{|c|}{ Nama } & RKH 1 & RKH 2 & RKH 3 & RKH 4 \\
\hline 1 & Dzakir & BSB & BSB & BSB & BSB \\
\hline 2 & Siddiq & BB & BSH & BSH & BSH \\
\hline 3 & Mhd. Saad & BSH & BSH & BSH & BSB \\
\hline 4 & Nanda Arjuna & BSH & BSH & BSH & BSB \\
\hline 5 & Luthfi & BSH & BSH & BSB & BSB \\
\hline 6 & Fauzi & BB & MB & BSH & BSH \\
\hline 7 & Habibullah & BB & BB & BSH & BSH \\
\hline 8 & Alzam & BSH & BSB & BSB & BSB \\
\hline 9 & Niko & BB & BB & MB & BSH \\
\hline 10 & Atha Ridho & BB & BB & BB & BB \\
\hline 11 & Fatih & BB & BB & BB & BB \\
\hline 12 & Zaid & BSH & BSB & BSB & BSB \\
\hline 13 & Herlangga & BB & BB & BB & BB \\
\hline 14 & Faizi & BSH & BSB & BSB & BSB \\
\hline 15 & Sami Athaya & BB & BB & BB & MB \\
\hline 16 & Azzahra & BSH & BSB & BSB & BSB \\
\hline 17 & Desriyanti & BSH & BSH & BSH & BSB \\
\hline 18 & Husna & BB & BB & BB & MB \\
\hline 19 & Nur Afifa & BB & BB & BB & BB \\
\hline 20 & Afiqah & BSH & BSH & BSH & BSB \\
\hline
\end{tabular}

$$
\mathrm{BB}=\mathrm{BELUM} \text { BERKEMBANG }
$$




\section{$\mathrm{MB}=$ MULAI BERKEMBANG \\ $\mathrm{BSH}=$ BERKEMBANG SESUAI \\ HARAPAN \\ $\mathrm{BSB}=\mathrm{BERKEMBANG} \mathrm{SANGAT}$ \\ BAIK}

Berdasarkan Tabel 4.1 didapatkan hasil bahwa kemampuan kolase anak-anak kelompok B TK NURUSSALAM mengalami peningkatan yang signifikan dan sudah sesuai dengan yang diharapkan. Hal ini terlihat dengan banyaknya dijumpai siswa yang mendapatkan nilai baik. Dari data di atas, dapat disimpulkan bahwa kemampuan membuat kolase anak kelompok B di TK NURUSSALAM sesuai dengan harapan guru

Gambar kegiatan anak membuat kolase dengan media kulit telur :
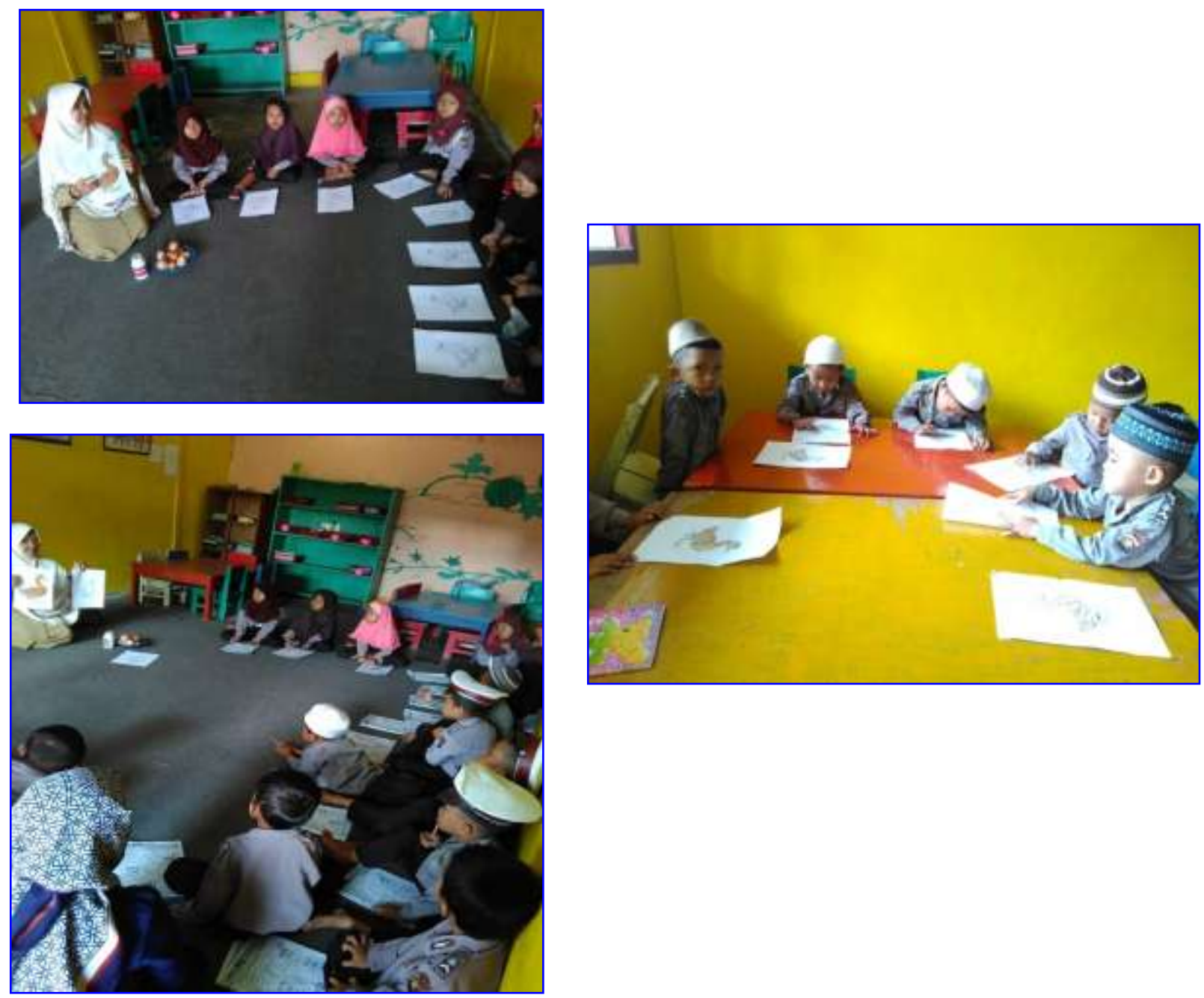

VOLUME 1, NO. 2 Juli - Desember 2019 


\section{Pembahasan}

Salah satu bentuk satuan pendidikan prasekolah di jalur pendidikan sekolah adalah Taman Kanak-kanak. Eksistensi dan esensi lembaga pendidikan Taman Kanak-kanak ini dalam kerangka pembangunan Pendidikan Nasional secara resmi diakui dalam Peraturan Pemerintah (PP) No. 27 tahun 1990. Menurut PP No. 27 tahun 1990, "Penyelenggaraan pendidikan Taman Kanak-kanak dimaksudkan untuk membantu meletakkan dasar ke arah perkembangan sikap, perilaku, pengetahuan, ketrampilan, dan daya cipta yang diperlukan oleh anak didik dalam menyesuaikan diri dengan lingkungannya, serta untuk pertumbuhan dan perkembangan selanjutnya."

Dari hasil penelitian tindakan kelas pada Rencana Kegiatan Harian menunjukkan bahwa kemampuan kolase anak kelompok $\mathrm{B}$ di TK NURUSSALAM sudah cukup baik. Hal ini dapat dilihat pada tabel 4.1, di mana pelaksanaan tindakan guru dengan menggunakan media kulit telur dan membagikannya kepada masing-masing anak, kemudian masing-masing anak diminta untuk mempraktekkan langsung yang didemonstrasi Guru.

Berdasarkan evaluasi yang dilakukan pada RKH 1 didapatkan hasil kemampuan pada anak kelompok B di TK NURUSSALAM $5 \%$ berkembang sangat baik, $45 \%$ berkembang sesuai harapan, dan 50\% belum berkembang. Pada RKH 2 didapatkan hasil kemampuan pada anak kelompok B di TK NURUSSALAM25\% berkembng sangat baik, 30\% berkembang sesuai harapan, 5\% mulai berkembang, dan 40\% belum berkembang. Pada RKH 3 didapatkan hasil kemampuan pada anak kelompok B di TK NURUSSALAM 30\% berkembang sangat baik, 35\% berkembang sesuai harapan, 5\% mulai berkembang dan $30 \%$ belum berkembang. Pada RKH 4 didapatkan hasil kemampuan pada anak kelompok B di TK NURUSSALAM50 \% berekmbang sangat baik , $20 \%$ berkembang sesuai harapan, 10\% mulai berkembang dan 20 $\%$ belum berkembang.

Pelaksanaan tindakan dalam penelitian ini mampu meningkatkan kemampuan anak dalam membuat kolase dengan media kulit telur. Adanya pembelajaran ini, anak dapat melatih kemampuan motorik halus anak dan 
mengembangkan kreativitas anak. Selain itu, guru pun dapat mengetahui apakah anak sudah mampu untuk membuat kolase, dan untuk mengetahui sejauh mana pemahaman siswa terhadap materi kolase dengan media kulit telur. Tindakan ini hanya dilakukan dalam empat hari, karena tujuan yang diinginkan telah tercapai dan kemampuan anak mengalami peningkatan.

\section{E. PENUTUP}

\section{Kesimpulan}

1. Melalui penggunaan media dengan metode demonstrasi dan pemberian tugas dapat meningkatkan kemampuan motorik halus (kolase) anak pada kelompok B TK NURUSSALAM.

2. Penelitian dilaksanakan di TK NURUSSALAM dengan tujuan untuk perbaikan pembelajaran di TK NURUSSALAM kelompok B, yang tujuan utamanya adalah meningkatkan kemampuan motorik halus kolase anak melalui tahapantahapan dalam PTK.

3. Kemampuan kolase anak-anak kelompok B TK NURUSSALAM sudah cukup optimal/baik sesuai dengan yang diharapkan.

\section{Saran dan Tindak Lanjut}

Berdasarkan hasil kesimpulan, ada beberapa hal yang sebaiknya diterapkan oleh guru dalam meningkatkan kualitas mengajarnya, khususnya dalam pengembangan seni dan fisik motorik anak kolase dengan berbagai media. Adapun saran-saran penulis sebagai berikut :

1. Gunakanlah alat peraga yang tepat dan menariksesuai dengan materi kegiatan sehingga pembelajaran dapat menghasilkan hasil belajar yang optimal.

2. Dalam memberikan tugas pada anak terlebih dahuluguru harus memperkenalkan media yang akan digunakan, dan gunakanlah media yang menarik bagi anak sehingga anak antusias terhadap kegiatan yang akan dilakukan. Dengan demikian akan membantu kemampuan anak dalam membuat kolase agar lebih meningkat.

3. Lihatlah emosi dan perasaan anak, jangan biarkananak berebut, tapi untuk 
mencoba bersama. Buatlah kelompok kecil agar anak maksimal dapat mencoba semua secara bergantian dengan teratur.

4. Fasilitas dalam pembelajaran sangat diperlukan gunamemotivasi anak dalam menumbuhkan kemampuan kolase anak.

5. Pemberian nilai itu sangat penting, di sampingsebagai hadiah, juga dapat memotivasi siswa untuk meningkatkan belajar serta sebagai laporan untuk orang tua di rumah.

6. Segala sesuatu yang diperoleh selama kegiatan PTKyang sekiranya dapat meningkatkan kemampuan anak, sebaiknya disampaikan kepada teman-teman sejawat atau Kelompok Kerja Guru (KKG). Sehingga teman yang lain mendapatkan masukan terhadap strategi mengajarnya.

Itulah beberapa kesimpulan dan saran yang dapat penulis sampaikan, semoga penelitian ini dapat bermanfaat bagi penulis sendiri pada khususnya, dan bagi rekan-rekan guru seprofesi pada umumnya.

\section{DAFTAR PUSTAKA}

Hamzah B. Uno, Nina Lamatenggo, Teknologi. Komunikasi dan Informasi Pembelajaran. Jakarta: Bumi Aksara, 2011.

Imam Wahyudi, Panduan Lengkap Uji Sertifikasi Guru, (Jakarta: PT. Prestasi Pustakarya, 2012.

Jamil Suprihatiningkrum, Guru Profesional : Pedoman Kinerja, Kualifikasi \& Kompetensi Guru, Yogyakarta: Ar-Ruzz Media, 2014.

Jejen Musfah, Peningkatan Kompetensi Guru : Melalaui Pelatihan dan Sumber Belajar Teori dan Praktik, Jakarta: Kencana, 2012.

Rusman dkk, Pembelajaran Berbasis Teknologi Informasi dan Komunikasi . Jakarta : Grafindo Persada, 2012.

Suyanto dan Asep Jihad, Menjadi Guru Profesional: Strategi Meningkatkan Kualifikasi dan Kualitas Guru di Era Globalisasi, Jakarta: Erlangga, 2013.

Rika Ariyani, Editor Jurnal Literasiologi. Literasi Kita Indonesia. STAI Syekh Maulana Qori. 